Check for updates

University College London, UK

c.pagel@ucl.ac.uk Follow Christina on Twitter: @chrischirp Cite this as: BMJ 2021;374:n2115 http://dx.doi.org/10.1136/bmj.n2115 Published: 01 September 2021

\title{
Schools: a gaping hole in England's covid strategy
}

\section{England is an anomaly in not undertaking any of three common strategies to prevent transmission in schools, says Christina Pagel}

\section{Christina Pagel director, Clinical Operational Research Unit}

The highly transmissible delta variant of SARS-COV-2 is now dominant in Europe and North America. While vaccinations are protecting adults from severe disease quite effectively, children remain mostly unvaccinated. In England, the rate of children being admitted to hospital with covid-19 reached its highest of the entire pandemic at the end of July 2021 (an average of 53 admissions a day), just after the school term ended.

The surge in cases and hospital admissions in children started after the summer half term holiday in early June, once delta was dominant and after the country moved to step 3 of the government's roadmap. Although ascertained cases and hospital admissions in children have fallen over the summer holidays, admissions of under 18 s remain near the January peak (about 40 admissions a day in mid-August). Current overall case rates in England are five times higher than in early June ( $25000 v 5000$ ) and are rising slowly. Children will return to school in a week or two.

The recent schools infection survey by the Office for National Statistics (ONS) reported that case rates in schoolchildren were lower in June 2021 than in November 2020. ${ }^{2}$ It concluded that schools in England were not "hubs of infection," partly owing to measures in place last summer such as frequent testing, isolation of contacts of new cases in schools, mask wearing (which continued in many schools even after 17 May 2021, when this was no longer mandatory), and low rates of covid in the community.

Unfortunately, the November 2020 and June 2021 figures both miss the peaks of infections in school age children, which came in December 2020 and July 2021. The main ONS infection survey concurred that prevalence in school age children was lower in late June $2021(<1 \%)$ than in November $2020(1-2 \%)$, but it reported similar rates in late July 2021 (2.0-3.5\%) and mid-December 2020 (2-3\%). This is also consistent with peak hospital admissions in children (to date) occurring last month. ${ }^{3}$

For schools to be a problem, they don't have to be worse than any other crowded indoor space. The problem is that they simply are another crowded indoor space, one where children spend 35 hours a week. We know that the delta variant spreads easily in such spaces, particularly if they are poorly ventilated. This is compounded by the fact that children are now the population group with the least immunity to covid because they remain largely unvaccinated. Children in the US returned to school in early August in the context of already high community rates in many states, and the numbers of children in hospital with covid there are now higher than ever. 4

If we want to avoid more hospital admissions of children this autumn in England we need to get their cases low, and keep them low, as they return to school. There are three ways to achieve this, and they work most effectively when used together.

\section{Vaccines}

Vaccines for 12-17 year olds have been approved in many countries, including the UK, but there is no licensed vaccine for under 12s. Most high income countries are now offering the vaccine to all 12-17 year olds, including the US, Germany, France, Italy, Spain, Canada, China, Japan, Israel, Ireland, Mexico, Indonesia, and Singapore. As of mid-August the UK is offering vaccines only to 16-17 year olds and a small group of 12-15 year olds defined as clinically extremely vulnerable. Vaccines have been shown to be highly effective in adolescents in preventing both symptomatic infection and severe illness and would act to reduce transmission in secondary schools. ${ }^{5}$

\section{Public health protective measures}

Countries have used a variety of measures to reduce transmission within schools, but most include social distancing (smaller class sizes, staggered breaks); ventilation ( $\mathrm{CO}_{2}$ monitors, HEPA filters, window policies, outdoor learning); cleaning surfaces; mask wearing; keeping children within bubbles of regular contacts; frequent testing; and isolation of contacts of cases.

Given delta's infectiousness, the European Centre for Disease Prevention and Control has updated its school guidance to recommend a combination of interventions in schools to keep transmission low and protect children this autumn. ${ }^{6}$ The US Centers for Disease Control has also updated its guidance to recommend masking by all staff and all students over the age of 2, physical distancing, testing, isolation, and ventilation to help keep transmission down in schools, alongside vaccinating adolescents. ${ }^{7}$

\section{Community rates}

As highlighted by the ONS survey on school infections, ${ }^{2}$ perhaps the biggest impact on cases in school age children is from rates of general transmission in the community. When cases are high in general, it's much harder to keep cases down in school settings.

\section{England is an outlier in its approach}

Most countries are using a combination of two or three of those approaches to allow children to return 
to school more safely. For instance, countries such as Norway and Japan have combined low community transmission and preventive measures in schools. Others with higher rates of community transmission, such as parts of the US, France, and Spain, are combining vaccinating adolescents and public health measures. Closer to home, schools in Ireland and Scotland are receiving $\mathrm{CO}_{2}$ monitors to monitor whether windows need to be opened, and masks are being maintained in secondary schools.

England is an anomaly in that it is undertaking none of the three strategies to prevent transmission in schools. While 16-17 year olds are now eligible for vaccination, most 12-15 year olds remain ineligible despite two approved vaccines (Pfizer and Moderna) and a clear majority of parents saying that they would vaccinate their children. $^{8}$

Almost all protective health measures have been removed for the coming school term: there will be no national requirement for mask wearing; no rollout of $\mathrm{CO}_{2}$ monitors or general support for ventilation; no social distancing; no bubbles; no requirement for under $18 \mathrm{~s}$ to isolate if a household member has covid; and minimal contact tracing within schools if a child tests positive.

Finally, community rates in England remain very high. With almost all public health measures removed and full capacity events such as football matches restarting, not only is the government not achieving low rates of transmission but it's not even trying to.

Under current policies, this next school term is likely to see extremely high cases in children again, with a few thousand more children requiring hospital admission. Even the lowest current estimate of $2 \%$ for rates of long covid in children will see thousands more children end up with long term symptoms. ${ }^{9}$ For many of the rest, even a mild course of illness will result in a week or two of missed school-a significant disruption. Clinically extremely vulnerable children are left in a precarious situation with no protection from exposure to a disease that could be very serious for them.

While Israel is considering delaying the start of its school year, the American Academy of Pediatrics is calling for vaccines to be extended to under 12s, and Canada warns of increased severity of delta infections in children, England is increasingly alone in adopting a stance that effectively suggests infections in children are nothing to worry about. ${ }^{10}$ I believe that we need to join our international colleagues, take infections in children seriously, and urge the government to follow international best practice as laid out by the European and US Centers for Disease Prevention and Control, to make schools as safe an environment as possible.

Christina Pagel is director of the Clinical Operational Research Unit at University College London and a member of Independent SAGE.

Competing interests: None declared.

Provenance and peer review: Commissioned, not peer reviewed

Gov.uk. Coronavirus (covid-19) in the UK. Updated Aug 2021. https://coronavirus.data.gov.uk/

2 Office for National Statistics. Covid-19 schools infection survey, England: round 6, June 2021. 11 Aug 2021. https://www.ons.gov.uk/peoplepopulationandcommunity/healthandsocialcare/conditionsanddiseases/bulletins/covid19schoolsinfectionsurveyengland/round6june2021

3 Office for National Statistics. Coronavirus (covid-19) infection survey, UK: 9 July 2021. 9 Jul 2021 https://www.ons.gov.uk/peoplepopulationandcommunity/healthandsocialcare/conditionsanddiseases/bulletins/coronaviruscovid19infectionsurveypilot/9july2021\#age-analysis-of-the-numberof-people-who-had-covid-19

4 US Centers for Disease Control and Prevention. Covid data tracker weekly review. 20 Aug 2021. https://www.cdc.gov/coronavirus/2019-ncov/covid-data/covidview/index.html

5 US Centers for Disease Control and Prevention. Covid-19 vaccines for children and teens. Updated 17 Aug 2021. https://www.cdc.gov/coronavirus/2019-ncov/vaccines/recommendations/adolescents.html
6 European Centre for Disease Prevention and Control. Covid-19 in children and the role of school settings in transmission-second update. 8 Jul 2021. https://www.ecdc.europa.eu/sites/default/files/documents/COVID-19-in-children-and-the-role-of-school-settings-in-transmissionsecond-update.pdf

7 US Centers for Disease Control and Prevention. Guidance for covid-19 prevention in K-12 schools. Updated 5 Aug 2021. https://www.cdc.gov/coronavirus/2019-ncov/community/schools-childcare/k 12-guidance.html

8 Office for National Statistics. Coronavirus (covid-19) latest insights: vaccines. 20 Aug 2021. https://www.ons.gov.uk/peoplepopulationandcommunity/healthandsocialcare/conditionsanddiseases/articles/coronaviruscovid19latestinsights/vaccines\#vaccine-attitudes

9 Molteni E, Sudre CH, Canas LS, et al. Illness duration and symptom profile in symptomatic UK school-aged children tested for SARS-CoV-2. Lancet Child Adolesc Health 2021; published online 3 Aug. https://www.thelancet.com/journals/lanchi/article/PIIS2352-4642(21)00198-X/fulltext

10 Tanne JH. Covid-19: Cases in children rise sharply in US as doctors call for vaccine approval. BMJ 2021;374:n2030. doi: 10.1136/bmj.n2030 pmid: 34400412

This article is made freely available for use in accordance with BMJ's website terms and conditions for the duration of the covid-19 pandemic or until otherwise determined by BMJ. You may use, download and print the article for any lawful, non-commercial purpose (including text and data mining) provided that all copyright notices and trade marks are retained. 